\title{
Platón y la conformación del Estado I. Algunos elementos para pensar la ciudad y su legislación
}

\author{
Plato and the establishment of the State I. Some items \\ to think about the city and its legislation. Ethics and the \\ challenge of living as democratic citizens
}

\section{Platão e a conformação do Estado I. Alguns elementos para pensar a cidade e sua legislação. A ética e o desafio de viver uma cidadania democrática}

Rodrigo Escobar San Martín ${ }^{1}$

Recibido: 28/07/2015 - Aceptado: 20/08/2015

\begin{abstract}
Resumen
Este artículo corresponde a una primera reflexión del Estado concebido por Platón. En este sentido, se analiza la importancia que tiene para Platón la polis y su relación con la filosofía. A partir de ello, la lectura que se pretende presentar encuentra su nicho principal en la obra Leyes. En una primera instancia, se persigue explicitar la importancia que posee la ley y su vínculo ético mediante las virtudes que debe poseer el Estado. Seguido de ello, se busca enfatizar el sentido de la paideia como propuesta éticapolítica en su politeia, abarcando ya no solamente a los gobernantes sino a todos los ciudadanos, para así promover una propuesta de gobierno teocrática-filosófica como respuesta a los regímenes políticos existentes, y principalmente a la democracia ateniense.
\end{abstract}

Palabras clave: polis - ética - política - ley - divinidad

Abstract

This article is a first reflection about the State conceived by Plato. It analyzes the importance of polis for Plato and its relation to philosophy.

1 Chileno, Profesor de Filosofía y Licenciado en Educación por la Universidad Católica Silva Henríquez. Actualmente se desempeña como profesor adjunto en la Universidad Católica Silva Henríquez. Contacto: rodrigo_escobarsm@hotmail.com 
Based on that, this reading presents its main niche in the work Laws. In first instance, it seeks to explicit the importance of law and its ethical link through the virtues that a State must have. Following, it seeks to emphasize the sense of paideia as an ethical and political proposal in its politeia, encompassing not only the rulers but all citizens in order to promote a proposal of philosophical theocratic government in response to the existing political regime, and mainly to the Athenian democracy.

Keywords: polis - ethics - politics - law - divinity

\section{Resumo}

Este artigo corresponde a uma primeira reflexão do Estado concebido por Platão. Neste sentido, analisa-se a importância que tem para Platão a polis e sua relação com a filosofia. A partir disto, a leitura que se pretende apresentar encontra seu nicho principal na obra Leis. Numa primeira instância, procura-se explicitar a importância que possui e seu vínculo ético através das virtudes que deve possuir o Estado. Após isso, se procura enfatizar o sentido da paideia como uma proposta ético-política em sua politeia, abrangendo não só aos governantes, mas a todos os cidadãos, a fim de promover uma proposta de governo teocrático-filosófica em resposta aos regimes políticos existentes, e, principalmente, a democracia ateniense.

Palavras-chave: polis - ética - política - lei - divindade

"Creo que soy unos de los pocos atenienses, por no decir el único, que se dedica al verdadero arte de la política y el único que la practica en estos tiempos" (Gorgias 521d).

\section{Filosofía y ciudad}

Parte importante de la forma y estilo de vida en la Grecia antigua tiene directa relación con la polis, centro de la vida pública. La idea del quehacer y de la organización política es entendida por los griegos como la forma de desarrollo preeminente de la humanidad, ya que otorga, por una parte, una morada en la cual cobijarse, y, por otra parte, permite al hombre sobrevivir. De ahí la importancia de la polis, único lugar en que es posible el desarrollo de la vida política.

Según Platón, vivir en comunidad es algo propio de las relaciones humanas, toda vez que resulta oportuno reunirse en función de conseguir el abastecimiento vital. Para ello, quienes participan de la comunidad 
se congregan en un mismo lugar por necesidad: "En tal caso, cuando un hombre se asocia con otro por una necesidad, habiendo necesidad de muchas cosas, llegan a congregarse en una sola morada muchos hombres para asociarse y auxiliarse. ¿No daremos a este alojamiento común el nombre de 'Estado'?" (República 369c).

Platón ve en las necesidades para sobrevivir el punto de partida para la fundación del Estado, pues un hombre por sí solo no puede satisfacerlas y requiere asociarse con otros hombres para su propia subsistencia. Tres son las necesidades sustanciales que Platón prioriza: en primera instancia, la provisión de los alimentos, por los cuales podemos vivir; seguido de ésta, la vivienda; y por último, la vestimenta (República 369d).

Para que surja la ciudad debe haber necesidades en los hombres, no obstante, Platón distingue una segunda razón que guarda relación con la rememoración.

La rememoración es vital desde el punto de vista platónico, y en este caso particular rememorar implica una relación inherente a la existencia de un pasado remoto en el que una gran civilización fue extinta producto de un cataclismo ${ }^{2}$. Luego de este gran cataclismo, se genera un nuevo orden en el espacio, y a pesar de que muere gran cantidad de hombres y animales, los pocos sobrevivientes tienen algún recuerdo de lo que implica vivir en comunidad. Producto de ello, la vida en comunidad vuelve progresivamente a surgir: a partir del pastoreo y la agricultura, poco a poco la raza humana comienza a multiplicarse, surgiendo nuevamente ciudades y sistemas políticos hasta llegar a la situación actual (Leyes 677a-678c).

Esta interpretación de Platón no es extraña para un heleno de su época: el mundo griego se encuentra supeditado al ámbito de la ciudad que encarna lo nuevo y lo civilizado. La polis griega unificó a los hombres y fue el punto de encuentro donde la actividad política se hizo posible.

2 De ahí también se ha querido ver -o mejor dicho, desprendido- una lectura sobre la posibilidad de una gran civilización extinta. La famosa Atlántida, interpretación que ha encontrado su razón de ser en la lectura del Timeo, más ciertas líneas interpretativas extraídas de la comparación con otros diálogos, tales como República y Leyes. 
La vida en comunidad, al reunir a los hombres en un mismo espacio, se encuentra impregnada con el significado de la palabra griega phylia (reunión, amor, amigo), porque es en ella donde se concibe el acto íntimo de identidad con el espacio que se habita y a su vez es familiar para la comunidad. Más aún, en este lugar es precisamente donde se esgrimen hábitos que son comunes para todos. La polis tiene un carácter formativo y espiritual, es decir, ser griego, según Vidal-Naquet (33), no es producto de nacimiento sino de educación: es un efecto de la paideia (Jaeger 2005). Esta identificación con el espacio hace que el griego ${ }^{3}$ se considere heleno separándose de las otras civilizaciones no griegas a las que calificará antiguas y bárbaras. Nomenclatura, por lo demás, que se encuentra a lo largo de toda la obra de Platón ${ }^{4}$.

En cuanto al fundamento de la polis, Platón entiende la vida buena como una reunión y como un ordenamiento, ésta sólo puede vivirse en comunidad, motivo por el cual habría una imposibilidad de pensar en una vida buena fuera de la ciudad. El hombre en su individualidad es transitorio y no puede alcanzar por sí mismo el pleno desarrollo que sí se puede dar en una vida comunitaria. Una sociedad en la que se complementan los hombres recíprocamente abarcaría todo lo que se requiere y se necesita para su existencia. El individuo puede sobrevivir en una comunidad basándose en su organización política.

En la ciudad, la obra creadora del hombre puede alcanzar plenitud espiritual, este espacio es propicio para el cultivo de la humanidad y es el único que puede cimentar una verdadera civilización. Por esta razón, Platón desprende la tesis de que el individuo no difiere en su totalidad de la ciudad, porque el funcionamiento de la ciudad es producto de

\footnotetext{
${ }^{3}$ Debe recordarse que cuando se habla de lo griego o de Grecia, se hace referencia principalmente a una abstracción, debido a que en dicha época no existe una nación griega como actualmente se conoce, sino más bien ciudades (poleis) griegas.

4 Claro está que debemos ser precavidos, pues sería pretensioso establecer un juicio universal acerca del bárbaro en la obra de Platón. A la hora de hablar acerca del bárbaro, existen matices y visiones a favor y en contra de este "otro" no griego. El planteamiento que se estipula es que el vocablo bárbaro se encuentra en oposición de lo griego, y Platón -como buen griego- utiliza la palabra en un sentido que es común del mundo helénico.
} 
acciones individuales al igual que nuestro organismo. Por una parte, Platón explica la división tripartita de alma en función del lugar que ocupan en el cuerpo (Timeo 69a-71b); por otra parte, la explicación tripartita del alma se halla en la división de clases sociales en la politeia (República 580d-581c). En ambos -individuo y polis-, las actividades realizadas se concentran en un sistema; esta unidad de lo humano es llevada a su vez a gran escala: la unidad de la ciudad. Este paralelismo que vislumbra Platón en su concepción política refleja, según Jaeger, una realidad que debe expresarse en el quehacer diario de la ciudad:

El Estado ideal que Platón representa es el Estado-ciudad. Su criterio coincide en este punto con la realidad de la vida política, tal como se había ido desarrollando a lo largo de la historia de Grecia. Alguna que otra vez califica a su Estado de ciudad griega, pero no representa la nación de los griegos, sino que a su lado coexisten otros Estados helénicos, con los que aquélla puede hallarse en paz o en guerra. No es, pues, la estirpe griega de sus habitantes lo que sirve de fundamento a su existencia como Estado. El Estado ideal de Platón podría realizarse lo mismo entre los bárbaros, y hasta es posible que haya existido alguna vez entre ellos, en tiempos pasados, sin conocimiento nuestro (647).

La polis es el gran espacio en que se generan diversas actividades, lo que obliga a contar con un mecanismo de intercambio de aquellas cosas fabricadas por los ciudadanos. Entonces, surge un lugar que hace posible la compra y venta: el mercado, donde el medio de cambio fue la moneda (República 371b). Este ejemplo de organización política formulado por Platón es una manera de expresar la constitución que tiene como telos una comunidad en que los hombres puedan llevar una vida plena y feliz, cuya función política se encuentra en concomitancia con la función fisiológica de los órganos en un gran sistema ${ }^{5}$. Por lo tanto, cada uno de los individuos debe llevar a cabo la realización de las tareas que le son propias, contribuyendo al orden y bienestar del sistema (República 370a-b).

\footnotetext{
5 Para Sócrates, el alma humana tiene una consecución estrictamente moral. Platón, siguiendo la línea de su maestro, añade a la concepción del alma humana un estatuto ontológico.
} 
La preocupación que tuvo Platón por la ciudad fue significativa. Esta preocupación para Constantino Tsatsos es la verdadera preocupación de todo hombre político:

La Idea es el principio de la vida política y en virtud de su carácter general nos guía con firmeza por entre las incertidumbres provocadas por la casualidad y las tentaciones de la realidad. La Idea de la acción social y política y, como corolario, la de la organización política que nace de esa acción, representa la principal preocupación del verdadero político (124).

Filosofía y política cumplen un rol gravitante en el pensamiento platónico. Esta idea queda de manifiesto en las inquietudes que Platón tenía en su juventud: "antaño, cuando yo era joven, sentí lo mismo que les pasa a otros muchos. Tenía la idea de dedicarme a la política tan pronto como fuera dueño de mis actos" (Carta VII 324b). Su intranquilidad por la ciudad se debe a que los grandes gobernantes que tuvo Atenas no se ocuparon de un orden moral y cohesión social basado en la justicia, sino más bien su quehacer político se ocupó de manera principal en equipar materialmente a la ciudad (Gorgias 518e$519 b)$. Platón plantea, no obstante, que gobernantes e individuos deben encontrarse sometidos al bienestar de la comunidad.

De esta manera aparece la filosofía, adquiriendo en la ciudad un rol preponderante. Podemos advertir que la filosofía nace en la ciudad y sin ella ésta deja de existir. Filosofía y ciudad son afines, ya que ambas se encuentran inmersas en la idea de lo nuevo. En el mundo griego surge la filosofía, refiriéndose ésta a aquello que es propio de lo griego, vale decir, la polis. Con justa razón, Vernant argumenta al respecto:

La razón no se descubre en la naturaleza, está inmanente en el lenguaje. No se forma a través de las técnicas que operan sobre las cosas; se constituye por la puesta a punto y el análisis de los diversos medios de acción sobre los hombres, de todas estas técnicas de las que el lenguaje es el instrumento común: el arte del abogado, del maestro, del orador, del hombre político. La razón griega es la que 
permite actuar de forma positiva, reflexiva, metódica, sobre los hombres, no de transformar la naturaleza. En sus límites, al igual que en sus innovaciones, aparece como hija de la ciudad (1985 364).

Para vivir en comunidad primero debemos comprender nuestra naturaleza: "para saber lo que es bueno para todos hay que comprender primero su naturaleza, de manera que para saber lo que es bueno para la raza humana debemos 'conocernos a nosotros mismos' mediante la comprensión de la naturaleza humana (la psyché)" (Guthrie 1990 498). Esta exigencia planteada por Guthrie tiene sentido si se encuentra en estrecho vínculo con la Idea de Bien, entendida como la necesidad suprema que, a ojos de Platón, requiere un tipo adecuado de educación ${ }^{6}$.

Al reunirnos en la ciudad (phylia), dirá Platón, la filosofía no puede desembocar simplemente en un medio para alcanzar la sabiduría; más bien su finalidad será alcanzar una ciudad armónica. Ahí radica la importancia de que la filosofía sea política ${ }^{7}$. Filosofía y política tienen que ir de la mano, así lo entiende Tsatsos en la obra de Platón: "Platón como filósofo es, por lo mismo y en el sentido más preciso y elevado del término, un político" (123).

La phylia posibilita un punto de partida para el surgimiento de una identidad común, de la cual cada uno participa en su quehacer cotidiano. Razón por la cual Platón manifestó que lo más importante es el todo y no las partes, por lo que el obrar significa trabajar hacia un fin superior y común para todos. Forma de vida, costumbres, tradi-

\footnotetext{
${ }^{6}$ La referencia moral-educativa que Platón plantea a lo largo de la República es, al mismo tiempo, una crítica directa a la formación del ciudadano en la democracia ateniense. Tucídides plantea en el discurso Fúnebre -en boca de Pericles- que Atenas es la educadora de Grecia (Libro II). Como bien es sabido, Platón es bastante quisquilloso con la democracia, pues no solamente su oposición estriba en pertenecer a una familia aristocrática ateniense, sino que es un tema también de pathos: no perdonará al sistema de gobierno que enjuició y dictó sentencia de muerte a Sócrates, su maestro. 7 De ahí la importancia que se da a República; pero, sin embargo, no hay que olvidar el último texto que Platón nos legó: Leyes. Obra en que profundiza, madura y deja de lado muchas ideas de República. Por lo demás, también debemos decir que esta obra es poco leída en la actualidad.
} 
ciones en común tienen como locus la polis griega. El filósofo vive en este mundo griego, por ende sus inquietudes políticas remiten a lo que acontece en la ciudad. La preocupación de Platón por la ciudad implica reflexionar sobre el conjunto dialécticamente ordenado de las actividades creadoras del hombre en la ciudad. Todo ello tiene como finalidad una vida buena, porque el pensamiento de Platón -en concomitancia con gran parte del pensamiento griego- nos dice que lo que se reúne -phylia- es para un bien.

\section{Nomocracia o el Imperio de la Ley}

Como se ha planteado, la realidad política es al mismo tiempo un escenario orgánico en el cual el principio de cada individuo -las atribuciones del alma- se yuxtapone en el todo que es el Estado: ambos son unificados bajo una realidad intrínseca y propia del ser humano. En Leyes Platón plantea lo siguiente:

Después de los dioses, el alma es la más divina de todas sus posesiones porque es lo que a uno le es más propio. Todo lo que se posee es, para todos, de dos tipos. Las cosas superiores y mejores son las que gobiernan, mientras que las inferiores y peores son las esclavas. En lo que uno posee hay que preferir lo que es amo a lo que está sometido (Leyes 726a).

La polis se encuentra en correspondencia, en lo posible, hacia una contemplación (teoría) de lo divino. La polis debe poseer un estatuto racional en que kósmos (orden) y armonía reverberen las cualidades divinas que han de alcanzarse en la esfera humana, Nettleship nos dice al respecto que, "Para Platón, que tenía ante sus ojos la inquietud e inestabilidad de la vida política, una de las cosas más necesarias era la formación de un 'ethos' permanente en la sociedad, de un carácter tradicional capaz de resistir los choques del espíritu de partido y del capricho individual" (146). Platón, apelando al plano divino en política, proyecta una inquietud sobre la inestabilidad política en la que se encuentra inmerso. Sus planteamientos son un fiel reflejo de lo que acontece en su época, pues la guerra del Peloponeso y el gobierno 
tirano de los treinta ${ }^{8}$ son ejemplos claros y nefastos de la inestabilidad y corrupción que puede alcanzar la mala praxis política.

El orden tiene un rol fundamental en Platón. En un primer momento, Platón relata en la Carta VII su preocupación que lo alienta desde temprana edad por la política. Posteriormente, en República plantea la importancia de aquel hombre que tiene como misión dirigir al Estado o el cuidado que ha de tenerse en la formación del gobernante. Mientras que en Leyes su preocupación está orientada a la relación entre la ciudad y la actitud legislativa, cuya labor es la de mayor relevancia para el cuidado y robustecimiento de la ciudad. A tal punto que considera necesario un cuerpo legislativo para los legisladores -al que denomina junta nocturna-, cuyo rol será el de mayor importancia para la conducción del Estado. Por otro lado, Platón establece otra institución -los guardianes de la ley- quienes velan por el estricto acatamiento de la normativa y de quienes llevan a cabo dicha normativa, es decir, los magistrados. Ahora bien, en este último texto pondremos especial énfasis sobre el problema político en Platón en cuanto a la importancia de la ley.

El problema de la legislación es abordado de manera profunda precisamente en la última etapa de su pensamiento. En este sentido, la obra póstuma Leyes plantea como problema principal la fundación de Magnesia, cuyo sistema político ${ }^{9}$ debe ser planteado sobre la base de

\footnotetext{
8 Tras la caída de Atenas en el año 404 a. c., se instaura en la ciudad un gobierno conocido como los Treinta de Atenas. Este gobierno revisa la constitución ateniense intentando restaurar la antigua oligarquía. No obstante, el régimen del terror que fue impuesto -donde incluso participan parientes directos de Platón como es el caso de Critias, y, al que también Platón fue invitando a participar-, la persecución que fue implantada hacia algunos ciudadanos y la censura que el gobierno implementó a Sócrates que se le prohíbe proseguir con su enseñanza, lo llevó a la indignación y abstención de trabajar en un régimen que, en palabras de Platón, "era la vergüenza de aquella época" (Carta VII 324d-325a). Sobre la situación histórica de aquella época puede consultarse el análisis expuesto por Petrie $(195649,53)$.

9 A este respecto, la obra Leyes es una propuesta de carácter eminentemente normativa, por lo que está pensada para adaptarse y sufrir cambios, independiente del sistema político llevado a la práctica. Quizás es por ello que Platón expone a este sistema político como el segundo mejor, pues la descripción política que nos ha legado en su obra República es planteada como superior. En otras palabras, Platón se está citando y pone en relación la organización política propuesta en Leyes con el Estado descrito
} 
tres criterios, a saber: la unidad política, la amistad -phylia- entre los ciudadanos y la importancia del interés común por sobre el interés privado (739a-e). Bajo este supuesto, fundar una colonia y dar leyes, plantea esgrimir una base sólida de legislación donde aquellas personas que puedan vivir en un orden fundado en la ley no encontrarán mayores inconvenientes en los detalles de la legislación. En términos políticos, es la ley quien regula la vida de manera sabia y buena. Por este motivo la conducta de las futuras generaciones concuerda con las costumbres sociales propias de la polis. Platón defiende este propósito cuando plantea la falta que se ha llevado hasta el momento por parte del legislador: "ningún legislador parece haber reflexionado nunca acerca de que para legislar pueden usar dos instrumentos, persuasión y coacción, en la medida que sea posible aplicarlos a una multitud sin educación. Utilizan sólo uno de los dos" (Leyes 722b-c).

La persuasión y la coacción son los instrumentos que posee el legislador para la aplicabilidad de la ley. Estos dos elementos no son inventos de Platón, debido a que ya se encuentran y son utilizados en sistemas políticos que son conocidos por él. Por una parte, la persuasión es propia del sistema político ateniense, mientras que la coacción es propia del sistema político Lacedemonio. ¿Cuál es el problema entonces? Los legisladores de ambas ciudades dan énfasis sólo a uno de estos instrumentos, porque son las diferencias de estos dos grandes sistemas políticos que se encuentran en oposición (Vernant 1998 61, 79).

en República. Su conclusión tiene como consecuencia afirmar que la mejor propuesta es el gobierno de los filósofos desarrollado en República. Esto porque todo sistema político humano son mera imitaciones del gobierno divino. La polis de República es la imitación ejemplar. En cambio Leyes es la segunda mejor imitación, porque se trata de una constitución que el filósofo da por escrito -tal y como lo dice en Repúblicacuando el mismo no ejerce el poder, esto es, el imperio de la ley rige cuando el filósofo se encuentra ausente. La ley regirá el tiempo que sea necesario en tanto el filósofo aún no sea educado y, en consecuencia, no pueda ejercer el poder. Una vez el filósofo haya alcanzado plena madurez le corresponderá tomar posesión del poder, en ese momento podrá él -rey filósofo- o sus miembros -junta nocturna- finalizar las leyes complementando o cambiando las que estime conveniente. En ese momento un gobierno divino (intelectual y epistémico) se hallará por sobre la ley. 
El legislador debe ayudarse mediante la palabra -halagos, discursos bellos-, para convencer; no obstante, a quien no obedezca se le obligará (Leyes 660a). El legislador debe ordenar los asuntos humanos en orientación hacia el orden, remitiendo los bienes humanos hacia los divinos, y la divinidad en concordancia con el intelecto gobernante, razón por la cual Platón nos dirá al respecto: "Tras considerar esto, el que promulgó las leyes instituirá guardianes sobre todos ellos, unos que se guían por sabiduría, otros por la opinión verdadera, para que el intelecto, uniendo todas estas cosas, las haga obedientes a la temperancia y la justicia, no a la riqueza y a la vanidad"(Leyes 632c-d).

El problema de la polis se encuentra estrechamente vinculado a la esfera ética, y es ahí donde apunta su crítica: un Estado saludable debe encontrarse en concordancia con el cuidado y la promoción de cuatro virtudes cívicas: sabiduría, valentía, temperancia y justicia. Jaeger tiene razón cuando manifiesta que esta división de virtudes cívicas es concomitante con una crítica profunda a la antigua paideia (cap. IX). A partir de ello podemos decir que la genialidad de Platón en este ámbito no versa en su originalidad, sino más bien en una lectura que hace sobre las deficiencias de su propia época, es decir, en los límites a los cuales ha llegado la formación tradicional del ciudadano. Por lo tanto, una de las preocupaciones principales que posee la teoría política de Platón es la paideia: la educación de los hombres, en tanto ciudadanos como gobernantes. Ética y política encuentran su sentido en la educación.

El ciudadano, desde su niñez, debe aferrarse a la ley por medio de la costumbre $y$, posteriormente, una vez que haya terminado de educarse, su capacidad intelectiva dirá que obedecer la ley será lo mejor. El motivo que dará Platón no deja de ser interesante: en los preámbulos a la ley se dirá que por algún dios ha nacido lo que se está atendiendo en la legislación (Leyes $722 \mathrm{~d}$-e) ${ }^{10}$, instaurándose la ley a largo plazo como aquello considerado lo mejor y lo común y ejerciéndose como

10 En este lugar Platón apela a la virtud del artificio: su ejemplo estriba en la utilidad de los preámbulos en lo que se pretende ejecutar la ley al compararlos con los preludios de la música, ya que en los preludios, la música que la precede elabora las más admirables melodías que hechiza a quien la oye. 
fuente normativa de la comunidad a la que todos deben someterse. Para Platón, la fuente de la que emana toda su legislación se manifiesta en el vínculo que debe tener el intelecto con la sabiduría, de esta manera podrá ejercerse una buena conducción de la ciudad. Un ejemplo esclarecedor que formula es el fomento del valor en la lucha contra la búsqueda irracional del placer, Platón expresa que: "si la bebida en común fuera guiada de manera correcta, ¿qué gran beneficio obtendrían los particulares y la ciudad?"(Leyes 641b) ${ }^{11}$.

Cualquier medio o mecanismo legal que presente alguna forma de autodominio es digno de alabar, en cambio cualquier forma de relajo es sumamente dañina. Las leyes deben contribuir a asuntos de diversa índole, pues corresponde a éstas observar las relaciones de los ciudadanos atendiendo siempre lo mejor para la ciudad. El imperio de la ley amplía su mirada a la totalidad de los asuntos humanos, por lo que Platón no esconde el vínculo que debe existir entre la episteme y la ecuación ética-política al manifestar que, "el conocer la índole y el estado de las almas sería una de las cosas más útiles para ese arte cuya tarea es cuidar estos asuntos. Somos de la opinión, pienso, de que corresponde a la política" (Leyes 650b).

Por otra parte, para establecer una legislación de esta envergadura, se necesita un sistema político sustentable, que no se encuentra en correspondencia directa con el modelo de corte aristocrático planteado en República. Más bien delinea un sistema político que se encuentre en un justo equilibrio, como un malabarista, entre dos polos completamente opuestos y disonantes entre sí, vale decir, al más despótico: la tiranía; y el que entrega mayor libertad: la democracia. Desde un principio esto suena extraño, porque Platón insiste -en los primeros cinco libros de las Leyes- que para forjar un Estado sano necesariamente debe existir una especie de 'tirano virtuoso'. No obstante, el equilibrio que Platón expresa entre los dos polos opuestos es por medio del ethos, y específicamente por medio de la mesura:

11 Sobre el trato de la embriaguez por medio de la razón y basándose en la legislación son interesantes los pasajes $641 \mathrm{~b}-650 \mathrm{~b}$. 
Cuando percibimos una cierta mesura en cada uno de ellos, de los unos en el ejercicio del mando y de los otros en la búsqueda de libertad, vimos que entonces se daba en ellos de manera significativa una situación de bienestar, pero cuando se desplazaron hacia los extremos, uno en el sentido de la esclavitud, otros en el contrario, la situación no fue beneficiosa para los unos ni para los otros (Leyes 702e).

El desplazamiento por la mesura, si bien cumple un rol importante, no suple el problema de fondo: un tirano mesurado o la libertad mesurada no pueden ser perpetuos debido a la fragilidad de dicha relación. En consecuencia, ¿se puede denominar a un filósofo mesurado? Platón dirá al respecto más bien que el filósofo -en tanto gobernante- ejerce un control, tanto del ciudadano por medio de la razón, como de la ciudad por medio del acatamiento de las leyes. El filósofo promueve determinaciones legales precisas en su obra; el guardián de la ley tiene como tarea velar por el acatamiento y cumplimiento de éstas. Las leyes, como lo ha manifestado Platón, deben persuadir o en su defecto coaccionar. Por lo tanto, el mandato de la ley es total.

En este sentido, Platón comprende que la realidad debe ser entendida en su totalidad por medio de la razón y del orden, ya que es la base fundacional en el sistema político de su sociedad. La vida es sometida a la ley, articulando el alma humana a la ciudad. Por esta razón, para Platón es inherente la relación entre individuo y ciudad:

Todo hombre debe pensar acerca de todos los hombres que el que no ha servido no podría llegar a ser un señor digno de alabanza y que hay que ensalzar más el servir bien que el mandar bien, primero a las leyes, en la convicción de que éste es un servicio a los dioses; luego que los jóvenes sirvan siempre a los mayores y a los que durante su vida no han perdido los derechos civiles (Leyes 762e).

A partir de ello, Platón toma prestado de algunos sistemas políticos ideas fundamentales, pero las reformula para así complementarlas en 
su propia constitución ${ }^{12}$. Todo ello bajo la idea fundamental comunitaria: la phylia. No debemos olvidar que para los griegos lo disperso es el reflejo de lo caótico y puede conllevar los peligros de la destrucción.

La ley debe buscar aquello que es conveniente y adecuado para la ciudad. En consecuencia, busca alcanzar humanamente asemejarse a la divinidad. Por tal motivo, el énfasis de Platón en prescribir normas acerca de una institución de suma importancia para su ciudad, a saber: los guardianes de la ley (Leyes 752b-755b). Estas normas tratan sobre la vigilancia de las leyes, la supervisión de los registros, los límites de edad y duración del cargo público.

\section{Fundamento de la ciudad e imagen divina}

El fundamento esbozado por Platón en Leyes propone una crítica profunda a los sistemas políticos imperantes en su época. Este elemento refleja un profundo conocimiento por parte de Platón de las principales constituciones del mundo griego. No es extraño, por lo demás, encontrar a lo largo de toda esta obra una gran cantidad de ideas legislativas e institucionales provenientes de Creta, Esparta y Atenas, principalmente. Claro está, Platón utiliza dichas constituciones para su proyecto político con un énfasis claramente reformador, vale decir, toma prestados sutilmente aquellos elementos que encuentra necesarios para, no obstante, presentar una propuesta clara y distinta de las ya existentes.

Asegurar el imperio de la ley implica reflexionar sobre dos elementos centrales del argumento político que datan de la obra República (VI 499a-502c) y cuyas consecuencias serán los dos pilares, tal como las "estelas de Heracles", básicos de la estructura de la polis: conocimiento y consenso. Por medio del conocimiento se busca someter toda la estructura política a un kosmos en donde el rol dominante de la clase de los magistrados avalará la corrección de las normas imperantes; 12 Platón toma las ideas, principalmente, de los sistemas políticos dorios. Sobre todo
en lo referido a sus instituciones. 
en tanto que el poder de la magistratura se exterioriza a través de mecanismos de control rigurosos y atento a la responsabilidad de los actos individuales y del pueblo ante la ley. Con estos elementos, las consecuencias concretas del imperio de la ley esbozado por Platón se hallan en concordancia con la alta profesionalidad que debe poseer el Estado $^{13}$. La polis platónica es una politeia altamente centralizada en un poder jerárquico, cuyo objetivo es mantener la philía y el kosmos de la organización social.

De esta manera, Platón describirá en Leyes la importancia de la organización espacial en que cifra una ciudad de 5.040 ciudadanos (737e) y cuya concepción urbanística es minuciosamente planificada. Al mismo tiempo, Platón será bien crítico sobre la hospitalidad hacia el extranjero, debido a que la relación con otras polis dañaría el buen orden político. Entonces, se debe limitar el acceso de entrada a los extranjeros, como también limitar los viajes al exterior de sus ciudadanos (950a-953e).

Ante esto debemos decir lo siguiente: Platón esboza en República un modelo político que tiende a situarse lo más cerca posible a lo divino. El tipo de gobierno que allí se expresa es el de los mejores, de ahí también surge su imposibilidad, porque el gobierno de los mejores -aristoi- es aquel en que el poder se concentra en un individuo o en un grupo pequeño, el cual necesariamente tiende a su degeneración, según lo estipulado en Leyes. En cambio en Leyes, si bien es una segunda opción de un gobierno divino, su carácter legislativo posee una actitud de tipo normativo más explícita. Regirse por la ley constituye un proyecto político que puede realizar de manera más efectiva la

\footnotetext{
${ }^{13}$ A diferencia de lo que ocurre en Atenas. Las estructuras de poder y el desempeño de los cargos en la democracia estaban asignados a individuos no profesionales. Esta discusión sobre el político profesional versus el político no profesional propio de la democracia ateniense, se puede encontrar a lo largo de todo el corpus platónico, especialmente en los ejemplos sobre los artesanos, médicos y capitanes de barco como ilustraciones del hombre político. No es menester de este artículo revelar las reflexiones platónicas en torno a esta problemática, pues implicaría escribir un nuevo artículo al respecto. El lector puede encontrar referencias sobre este tema en las discusiones políticas de Platón con los sofistas.
} 
idea del bien en la comunidad, además de resguardarla mediante mecanismos restrictivos que salvaguarden el imperio de la ley en su aplicabilidad a la realidad de la ciudad. Podemos decir al respecto que en República, el Estado de Platón se funda principalmente en las Ideas:

Su Estado es el que acaba de erigirse y se funda en el mundo de las ideas, pues sobre la tierra este Estado no existe en parte alguna. Sin embargo el hecho de que exista o no -y con esto pone fin Platón a sus investigaciones- no supone ninguna diferencia. Tal vez exista en el cielo como eterno paradigma para quien quiera verlo $y$, con la vista fija en este modelo, desee fundarse a sí mismo como verdadero estado (Jaeger 2006 760-761).

Jaeger tiene razón en esta aseveración por dos razones: la primera tiene que ver con que el mismo Platón lo propone en su obra (República 592b); mientras que la segunda se relaciona con el cambio de tonalidad ${ }^{14}$ manifiesta en lo expresado en Leyes: "existe una gran esperanza de que, con toda probabilidad, si se establece según nuestro proyecto, llegue a ver al Sol y a los otros dioses dentro del pequeño número de las ciudades y regiones respetuosas de la ley" (950d).

Debemos recordar que Platón desde un comienzo establece la nomocracia bajo ciertas condiciones relevantes: la unidad que debe haber en la ciudad, la amistad entre los ciudadanos y el fomento del interés común por encima del privado. Junto con ello, Platón propone que el deber del hombre comprende ciertos criterios, tales como: amor a los padres, amor a los conciudadanos, valor, veracidad, autodominio. Por lo tanto, el sentido de la legislación -tanto individual como política-es la unidad, la espiritualidad y la moral:

\footnotetext{
14 Este cambio de tonalidad tiene que ver con el trato diferente de la paideia. En República la educación tiene como función directa la formación de gobernantes. En Leyes existe una paideia general; este cambio significativo de Platón en la reflexión sobre la paideia promueve no solamente la formación de gobernantes sino la formación de ciudadanos. Esto quiere decir que su énfasis está en la formación integral de todos aquellos, en tanto ciudadanos, que conforman la polis.
} 
Se forje un plan que para en lo posible también las cosas que son propias por naturaleza se hagan de alguna manera comunes, como que ojos, orejas y manos parezcan ver, oír y actuar en común, y todos alaben y critiquen al unísono lo más que puedan, alegrándose y doliéndose de las mismas cosas, $y$, por fin, las leyes que en lo posible hagan una ciudad unida al máximo (Leyes 739c-d).

Esta idea no es extraña, pues ya había sido estipulada por Platón en República: "Por lo tanto, el Estado mejor gobernado es aquel en que más gente dice lo 'mío' y lo 'no mío' referidas a las mismas cosas y del mismo modo" (462c).

En estos pasajes se anuncia una fuerte consonancia espiritual con los ideales griegos de la ciudad. La integración del alma y su correspondencia con las cuatro virtudes cívicas (República 429e-433a) tienen como correspondencia la salud del individuo como la salud integral de la ciudad. Medicina y política son inherentes al cuidado espiritual humano, la psyché (Mueller 1997 cap. V). La conservación de la ciudad mediante la obediencia irrestricta a la ley tiene como telos la preservación, porque es la manera en que la justicia, entendida como virtud política articuladora, integra a todas las demás virtudes cívicas (sophrosyne [moderación], andreía [valentía], sophía [sabiduría]) a un gran sistema de ciudad justa, feliz y saludable. Bajo esta óptica política, Platón incorpora en Leyes la virtud moral integradora (phronesis, traducido normalmente como mesura o temperancia) que debe imperar en la ciudad. Estos elementos para Platón entregarán un perfecto equilibrio y un control total de las pasiones, cumpliendo un rol significativo para aquellos que les llegue el momento de gobernar (Leyes 701e).

El aspecto fundante en la obediencia a la ley cumple un papel moral y político expresado en el amor (philía) como baluarte de la unidad que debe imperar en la ciudad, ya sea por medio de las leyes del Estado o por medio de las leyes internas que dicta la razón. La correspondencia es total.

La ley -al igual que la medicina- se establece como el enemigo natural de los vicios y las enfermedades humanas. El ejemplo que atribuye 
Platón a este supuesto es claro; el hombre posee ciertas dependencias naturales que pueden decantar en deseos degenerados: la dependencia de la comida puede degenerar en la gula, la dependencia de la bebida puede degenerar en embriaguez, y la dependencia sexual de procrear puede degenerar en la lujuria que Platón atribuye al desenfreno sexual (Leyes 782d-783a). La regulación de estas tres "enfermedades" que trae consigo el hombre debe estar sujeta a la legislación de las festividades, rituales y certámenes:

El legislador, volviendo a los ciudadanos hacia lo mejor, en contra de lo así llamado más placentero, debe intentar que refrenen estas apetencias como a tres enfermedades, con los tres medios más importantes: temor, ley y palabra verdadera, y que, utilizando, además, a las Musas y los dioses patronos de los certámenes, apaguen su crecimiento y su flujo (Leyes 783a-b).

Al igual que regular el desenfreno, o si es posible prescindir de él, la ley ayudará a limitar estos aspectos de la naturaleza humana, o, en su defecto, a censurarlos si acaso es lo necesario. Este ejemplo acerca de la naturaleza humana ilustra a su vez cómo la censura puede ser aplicada a otros campos, como es el caso de ciertas artes, ciertas profesiones y ciertas instituciones; pero por sobre todo la censura se encuentra pensada para la formación educativa que imperaba en la Grecia de su época. El deber de preservar la ciudad va de la mano con la esperanza de formar a un nuevo ciudadano. El compromiso del ciudadano es un compromiso público al servicio del Estado.

La relevancia de la ley en la praxis política debe situarse por encima de todas las acciones y todos los individuos. Debe reinar la idea de justicia instaurándose la razón por sobre la acción. Cumplir con la ley es deber de todos independientemente de su condición: tanto para el aristoi como para el plethos. Como ya se ha visto, con el advenimiento de la ciudad y su consolidación por medio de la ley, Platón, en primera instancia, antepone un preámbulo cuyo fin es convencer: "pues para que aquel al que el legislador dicta la ley reciba con buena disposición -y por la buena disposición sea más capaz de aprender- lo que de veras es la ley, el orden, me parece que se ha dicho todo ese discurso que el que habla dijo con la finalidad de convencer" (Leyes 723a-b). 
¿Qué significa convencer? En este caso particular Platón está mirando hacia el modelo divino: mirar hacia lo divino implica necesariamente adecuar a la humanidad hacia comportamientos aceptables para la divinidad: nomos y ethos irremediablemente van de la mano.

La simbiosis que Platón atribuye sobre estos puntos radica en el convencimiento de alcanzar, en la medida de lo posible, la realidad divina. El orden social encuentra su fundamento en la piedad puesto que el énfasis de la persuasión de la ley encuentra su raíz en la creencia de los dioses, esta creencia es cuestión política: los cultos a los dioses son públicos y no privados. De esta manera, el orden político adquiere su base en la teología, donde la aquiescencia que Platón da a este punto es clara: "dios debería ser la medida de todas las cosas" (Leyes 716c). La medida, a la que Platón da especial énfasis, tiene que ver con aquello que condiciona la realidad humana a la realidad divina, donde "es necesario, por tanto, que el que ha de llegar a ser querido por él -"dios" - se convierta lo más posible también él en un ser de esas características" (Leyes 716c-d, las comillas son mías); tal y como ya había sido antes planteado en República (613a-b). No resulta extraño que Platón siga la tradición griega, especialmente las enseñanzas de su maestro Sócrates, con algunas cuotas de pitagorismo y orfismo, en la firme creencia de que el hombre tiene un componente divino: la psyché. El alma es, después de los dioses, lo más divino y aquello que es propio del hombre. Platón dirige su mirada hacia la superioridad del orden divino, las fuerzas espirituales humanas deben dirigirse hacia ellas para gobernar; mientras que lo corpóreo e inmanente, a lo cual Platón atribuye una naturaleza de orden inferior $-y$ con ellas las sensaciones y el placer-, son necesariamente esclavas. Al mismo tiempo que Platón atribuye la analogía del alma, debemos considerar que "el prudente de entre nosotros es querido por el dios, pues es semejante, pero el que no es prudente es desemejante, diferente $y$ desigual" (Leyes 716d).

A partir de estos elementos Platón infiere que ha de preferirse lo que hay de digno y patrono en vez de lo indigno y sometido: "que es dios el que gobierna todo y que el azar y la oportunidad ejercen el gobierno de todos los asuntos humanos sólo con la ayuda de dios" (Leyes 709b). 
El argumento acerca de la superioridad teológica de la politeia de Platón es una respuesta directa al fundamento de una politeia antropológica de la sofística, que llevaba como estandarte el lema de Protágoras"15: "el hombre es medida de todas las cosas" (Crátilo 385e).

La referencia a lo divino tiene como consecuencia llevar al ser humano a la idea de que debe comportarse adecuadamente para que sus conductas sean aceptadas por la divinidad. He aquí algo que se encuentra entrelazado íntimamente con cada ser humano: la justicia es inherente al alma (Leyes 716a).

Mediante la mesura el hombre puede acercarse a dios, puesto que el sacrificio y la relación por medio de ofrendas o plegarias hará que el hombre pueda tener una vida feliz (eudaimonia). La eudaimonia, entendida como la conexión más adecuada con el daimon ${ }^{16}$, es un tipo de relación intrínseca y recíproca que tiene el hombre con la divinidad en su acción. Platón coloca especial énfasis en esa conexión: "cuando, en un ser humano, el poder más alto coincide con la inteligencia y la prudencia, se produce el nacimiento del mejor orden del gobierno y de las leyes correspondientes, pero que no ocurre nunca de otra manera" (Leyes 712a) ${ }^{17}$. El conocimiento filosófico constituye el fun-

15 La lectura que estamos siguiendo es eminentemente política. No obstante, no debemos olvidar que la discusión es más amplia y rica sobre este tema, tanto a nivel gnoseológico y ético, por citar algunos ejemplos. Al mismo tiempo se ha generado mucha controversia en cuanto a la interpretación de este fragmento de Protágoras. Para el lector me permito remitir dos estudios significativos de especialistas, dentro de la multiplicidad que existe, que le ayude a generar un panorama amplio sobre el tema: el primer estudio es el de Guthrie (1988 183 y ss.); el segundo es la obra monumental de Albin Lesky (1989 369 y ss.)

16 La referencia es directa a Sócrates, su gran maestro. Lo importante de esta relación consiste en el estrecho vínculo de toda conducta a lo largo de la vida bajo los principios de la racionalidad moral. En este sentido, Foucault (2006 15-38) plantea un análisis bastante interesante sobre la figura socrática en la Apología de Platón.

17 Por otro lado, es interesante traer a colación la argumentación que Platón sitúa a continuación sobre la actitud que posee el preámbulo de la ley en lo concerniente a la persuasión: "Hagamos como si un oráculo nos hubiera contado una leyenda que demuestra que, en un sentido, es difícil que una ciudad llegue a tener un buen orden político y legal, pero que, en otro, si realmente llegara a darse lo que decimos, sería por mucho lo más rápido y más fácil de todo". 
damento principal de la virtud que deben poseer los ciudadanos. En efecto, sigue persistiendo una exigencia que se arrastra de República, a saber: la unión del poder político y la sabiduría filosófica. Sugerentemente Platón nos sigue diciendo que está muy lejos de renunciar a los ideales políticos trazados en la obra República, es decir, no deja de lado su concepción del mejor Estado, pero esta vez con matices de orden práctico, pues al parecer todavía rondan por su cabeza las nefastas experiencias vividas en los viajes a Siracusa.

La educación del hombre permite alcanzar la mansedumbre o sumisión hacia la divinidad, esta es una de las ideas centrales que el viejo Platón imprime a lo largo de toda su obra Leyes. Claro está, siempre y cuando sea una educación correcta y su naturaleza esté en afinidad con la divinidad; por el contrario, si la ecuación no es la adecuada o es insuficiente, el hombre puede convertirse en el animal más salvaje de toda la tierra. Es por ello que la educación tiene una relevancia política-filosófica tan importante en su obra. Sería absurdo pensar que la educación juegue un papel secundario en la ciudad, porque conllevaría la degeneración y declive de la polis; este elemento es evidentemente crítico acerca de la lectura que hace sobre su época. Para Platón, las leyes como la ciudad han de custodiar por una educación completa y duradera, en que debe primar el orden y la unidad normativa de la ley. Junto con ello, es de suma importancia no relajarse en cuanto a la actitud de responsabilidad y compromiso que le compete al ciudadano para con la ciudad, de tal modo que prisiones y tribunales dejen de ser necesarios: "si la mayoría mantiene una actitud mesurada en estos asuntos, quede todo en silencio, sin legislación, pero si caen en el desorden, deben legislar de esta manera y luego actúen según las leyes dadas" (Leyes 784e-785a).

El carácter de una ley absoluta estipulada por Platón es el fiel reflejo de una sociedad pensada homogéneamente. Reformar la educación significa al mismo tiempo reformar al ciudadano, pero de sobremanera levantar una nueva arquitectura en que las afecciones políticas se encuentren en la convicción de que una buena politeia exige estructuralmente una formación filosófica. Ni siquiera el mejor Estado, nos dirá Platón, puede durar, pues es ley universal que todo lo engendrado por el hombre y por este 
mundo se descomponga. Las leyes que Platón promulga teóricamente apuntan precisamente a esto: a la existencia posible de una polis que pueda consolidarse el mayor tiempo posible. Mediante los instrumentos de la ley -persuasión y coacción- se busca que la constitución de este nuevo sistema político sea lo más cercano a la divinidad, en este sentido Castoriadis (2012 44) plantea que la búsqueda que Platón intenta llevar a cabo es una ley absoluta, una norma que trascienda a todas las normas, abarcando y desplegándose en toda la sociedad.

Como ya hemos visto, esta norma trascendente la fija en dios. En términos políticos es la brecha insalvable de contraponer a la democracia un proyecto político teocrático. Como plantea De Romilly (2010), Platón es fuertemente influenciado por Sócrates, su mentor filosófico, quien considera que el conocimiento es inherente a la ética, a diferencia de la sofística: Sócrates deambula por las calles de la democracia ateniense apelando al autocuidado con la firme convicción salvífica del juicio y los castigos del más allá, en que los mitos de los infiernos siempre juegan un rol importante; por otra parte se encuentra Protágoras, que sólo piensa en la ciudad y en los castigos humanos, pues la política no es asunto divino -del cual no hay certeza- sino humano.

En última instancia, la política de su época lleva a Platón a un diagnóstico acerca de los grandes problemas de las leyes imperantes. Más aún, esta problemática se encuentra entrelazada a toda la historia de la civilización humana:

Pues dicen que las leyes no apuntan ni a la guerra ni a la virtud total, sino que el orden político que está eventualmente instituido mira a lo que le conviene, con el fin de gobernar siempre y que no lo destruyan, y que por naturaleza la mejor definición de lo justo se da por naturaleza así. -¿Cómo? -Lo que es útil al más fuerte (Leyes 714c).

La agudeza de esta reflexión estriba en que la promulgación de las leyes se encuentra siempre sujeta a la consolidación del poder, ya sea de una autoridad o gobierno: un gobierno de gran poder requiere súbditos. Este pensamiento es propio del mundo griego que entiende a la libertad en oposición a la esclavitud, vale decir, una y otra son las dos caras de 
la misma moneda en cuanto a praxis política se refiere. Así lo expone Trasímaco en República (338c y ss.) y también Tucídides, en boca de Pericles, cuando en uno de sus discursos se refiere al imperio ateniense:

Este imperio que poseéis ya es como una tiranía: conseguirla parece ser una injusticia, pero abandonarla constituye un peligro. Ciudadanos como estos arruinarían rapidísimamente el Estado en caso de llegar a persuadir a los otros, o si se establecieran en alguna parte gobernándose por su propia cuenta; la tranquilidad, en efecto, no está libre de peligros si no se alinea junto a la acción, y vivir como esclavos en una situación de seguridad no es propio de una ciudad soberana, sino de una ciudad que es vasalla (II 63).

\section{Bibliografía}

Castoriadis, Cornelius. La ciudad y las leyes. Buenos Aires: Editorial Fondo de Cultura Económica, 2012.

De Romilly, Jacqueline. Los grandes sofistas de la Atenas de Pericles. Madrid: Editorial Gredos, 2010.

Foucault, Michel. La hermenéutica del sujeto. México D. F.: Editorial Fondo de Cultura Económica, 2006.

Guthrie, William Keith Chambers. Historia de la Filosofía Griega. Tomo III. Siglo V. Ilustración. Madrid: Editorial Gredos, 1988.

Guthrie, William Keith Chambers. Historia de la Filosofía Griega. Tomo IV. Platón. El hombre y sus diálogos: primera época. Madrid: Editorial Gredos, 1990.

Jaeger, Werner. Paideia: los ideales de la cultura griega. México D. F.: Editorial Fondo de Cultura Económica, 2005.

Lesky, Albin. Historia de la literatura griega. Madrid: Editorial Gredos, 1989.

Mueller, Fernand-Lcucien. Historia de la psicología. México D. F.: Editorial Fondo de Cultura Económica, 1997.

Nettleship, Richard Lewis. La educación del hombre según Platón. Buenos Aires: Editorial Atlántida, 1945.

Pabón, José Manuel. Diccionario de griego. Barcelona: Editorial Vox, 2005. 
Petrie, A. Introducción al estudio de Grecia. Historia, antigüedades y literatura, Fondo de Cultura Económica, México D. F., 1956.

Platón. Carta VII. Barcelona: Editorial Gredos, 2007.

Platón. Crátilo. Barcelona: Editorial Gredos, 2007.

Platón. Gorgias. Barcelona: Editorial Gredos, 2007.

Platón. República. Barcelona: Editorial Gredos, 2007.

Platón. Timeo. Barcelona: Editorial Gredos, 2007.

Platón. Leyes. Barcelona: Editorial Gredos, 2007.

Sofistas. Obras. Barcelona: Editorial Gredos: 2007.

Tsatsos, Constantino. La filosofía social de los antiguos griegos. México D. F.: Editorial UNAM, 1982.

Tucídides. Historia de la guerra del Peloponeso. Tomo I. Barcelona: Editorial Gredos, 2006.

Vernant, Jean-Pierre. Mito y pensamiento en la Grecia antigua, Barcelona: Editorial Ariel Filosofía, 1985.

Vernant, Jean-Pierre. Los orígenes del pensamiento griego, Buenos Aires: Editorial Paidós, 1998.

Vidal-Naquet, Pierre. El mundo de Homero. Buenos Aires: Editorial Fondo de Cultura Económica, 2007. 